\title{
Reversible Electrochemical Modulation of a Catalytic Nanosystem
}

\author{
Flavio della Sala, Jack L.-Y. Chen, Simona Ranallo, Denis Badocco, Paolo Pastore, \\ Francesco Ricci, * and Leonard J. Prins*
}

\begin{abstract}
A catalytic system based on monolayer-functionalized gold nanoparticles ( $A u$ NPs) that can be electrochemically modulated and reversibly activated is reported. The catalytic activity relies on the presence of metal ions $\left(\mathrm{Cd}^{2+}\right.$ and $\left.\mathrm{Cu}^{2+}\right)$, which can be complexed by the nanoparticle-bound monolayer. This activates the system towards the catalytic cleavage of 2-hydroxypropyl-p-nitrophenyl phosphate (HPNPP), which can be monitored by UV/Vis spectroscopy. It is shown that $\mathrm{Cu}^{2+}$ metal ions can be delivered to the system by applying an oxidative potential to an electrode on which $\mathrm{Cu}^{0}$ was deposited. $B y$ exploiting the different affinity of $\mathrm{Cd}^{2+}$ and $\mathrm{Cu}^{2+}$ ions for the monolayer, it was also possible to upregulate the catalytic activity after releasing $\mathrm{Cu}^{2+}$ from an electrode into a solution containing $\mathrm{Cd}^{2+}$. Finally, it is shown that the activity of this supramolecular nanosystem can be reversibly switched on or off by oxidizing/reducing $\mathrm{Cu} / \mathrm{Cu}^{2+}$ ions under controlled conditions.
\end{abstract}

Complexity is emerging as a major theme in chemistry. ${ }^{[1]}$ Not only does it mark a shift from the study of relatively simple molecules to complex molecular structures similar to those found in nature, but it also marks a shift from the study of single molecules to networks of molecules. ${ }^{[2-4]}$ Within the subfield of catalysis, ${ }^{[5]}$ the emergence of nanozymes, defined as nanomaterials with enzyme-like activity, nicely illustrates this development. ${ }^{[6]}$ Nanozymes are prepared following a bottom-up strategy relying on the use of simple synthetic components for the formation of structures with a size and structural complexity similar to that of enzymes. ${ }^{[7,8]}$ Their high stability, uniformity, and ease of modification is favoring applications in the fields of sensing, ${ }^{[9]}$ materials science, ${ }^{[10]}$ and systems chemistry. ${ }^{[11]}$ The observation that nanozymes can exhibit an emerging property such as cooperativity is indeed a sign that significant progress has been made in the design of functional complex systems. ${ }^{[12]}$ However, whereas nature has gained exquisite control over the complex biological machinery by using specific triggers to up- and down-regulate catalytic processes, similar regulatory pathways are still largely inexistent for nanozymes. Herein, we present

[*] Dr. F. della Sala, Dr. J. L.-Y. Chen, Dr. D. Badocco, Prof. Dr. P. Pastore, Prof. Dr. L. J. Prins

Department of Chemical Sciences, University of Padova

Via Marzolo 1, 35131 Padova (Italy)

E-mail: leonard.prins@unipd.it

S. Ranallo, Prof. Dr. F. Ricci

Chemistry Department, University of Rome Tor Vergata

Via della Ricerca Scientifica, 00133 Rome (Italy)

E-mail: francesco.ricci@uniroma2.it

(2) Supporting information and the ORCID identification number(s) for

(iD the author(s) of this article can be found under:

http://dx.doi.org/10.1002/anie.201605309. a simple setup for the reversible activation and modulation of nanozymes using an electronic input. The electrochemical activation is highly attractive because of its ease of implementation, cleanliness, precision, and rapid response. ${ }^{[13-16]}$ The availability of this kind of regulatory mechanism will strongly determine the success of chemists in constructing synthetic networks for studying complexity on the systems level.

The main component of our system is Au NP 1, which are gold nanoparticles $(d=1.5 \pm 0.3 \mathrm{~nm})$ covered with C9-thiols terminating with a 1,4,7-triazacyclononane (TACN) head group (Figure 1a). ${ }^{[11]}$ Such nanoparticle-bound TACN moieties are able to coordinate $\mathrm{Zn}^{2+}$-metal ions forming a supra-

a)
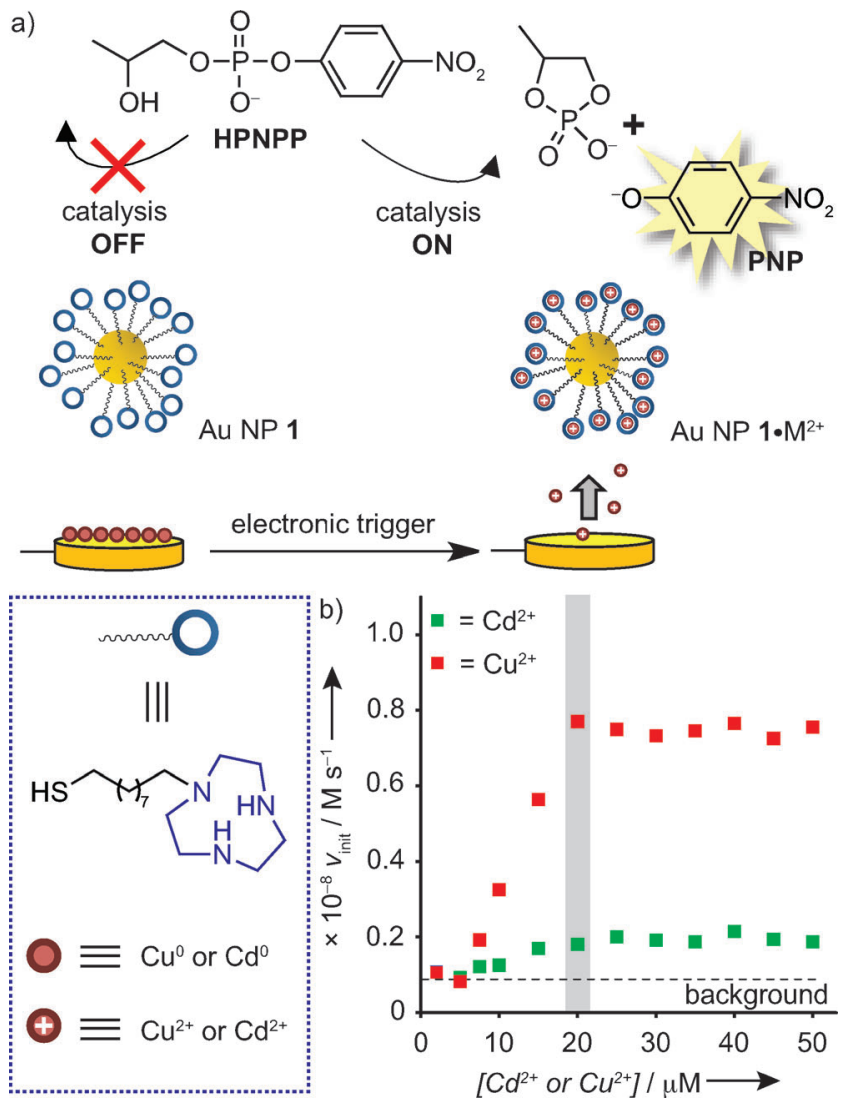

Figure 1. a) Representation of the activation of Au NP 1 through the electrochemically activated release of metal ions from an electrode. b) Initial rate $\left(\nu_{\text {init }}\right)$ of HPNPP transphosphorylation as a function of the concentration of $\mathrm{Cu}^{2+}$ (red) or $\mathrm{Cd}^{2+}$ (green). The gray bar marks the difference in reactivity of Au NP $1\left(\nu_{\text {init }}=8.6( \pm 1.9) \times 10^{-10} \mathrm{M} \mathrm{s}^{-1}\right.$, background), Au NP 1.Cu ${ }^{2+}\left(\nu_{\text {init }}=7.7( \pm 0.9) \times 10^{-9} \mathrm{M} \mathrm{s}^{-1}\right)$, Au NP $1 . \mathrm{Cd}^{2+}\left(\nu_{\text {init }}=2.0( \pm 0.3) \times 10^{-9} \mathrm{M} \mathrm{s}^{-1}\right)$ when $[\mathrm{TACN}] /\left[\mathrm{M}^{2+}\right]$ ratio is $1: 1$. Conditions: $[\mathrm{TACN}]=20 \mu \mathrm{M},[\mathrm{HPNPP}]=1 \mathrm{~mm},[\mathrm{HEPES}]=10 \mathrm{~mm}$, $\mathrm{pH} 7.0,25^{\circ} \mathrm{C}$ 
molecular catalyst that very efficiently promotes the transphosphorylation of 2-hydroxypropyl-p-nitrophenyl phosphate (HPNPP), a common substrate used for mimicking RNA-hydrolysis. ${ }^{[12]}$

The role of the nanoparticle support is critical, as the observed rate acceleration is due to the cooperative effect between TACN head groups in close proximity. Limited activity is observed for unbound TACN analogues. ${ }^{[12]}$ Extensive previous studies have shown that the system displays Michaelis-Menten-like catalytic activity, resulting from the formation of catalytic pockets between two neighboring NPbound TACN. $\mathrm{Zn}^{2+}$-complexes. ${ }^{[17]}$ For this reason, these systems have also been referred to as nanozymes. ${ }^{[12]}$ The numerous analogous multivalent systems (both molecular and NP-based) that have been reported require the presence of $\mathrm{Zn}^{2+}$ or other metal ions (for example, $\mathrm{Cu}^{2+}, \mathrm{Co}^{3+}, \mathrm{Ce}^{4+}$, $\mathrm{Fe}^{3+}$ ) for catalytic activity. ${ }^{[18]}$ The observation that $\mathrm{Au} \mathrm{NP}$ $\mathbf{1}$ and related systems are poorly active in the absence of metal ions implies that the controlled association and dissociation of metal ions can be used as a regulatory mechanism for catalysis. The low residual activity of non-metalated Au NP 1 presumably originates from the presence of protonated TACN-ligands, at neutral or acidic $\mathrm{pH}^{[19]}$

In this study, $\mathrm{Cu}^{2+}$ and $\mathrm{Cd}^{2+}$ metal ions were deliberately chosen for a number of reasons. Firstly, measurement of the catalytic activity as a function of the amount of $\mathrm{Cu}^{2+}$ and $\mathrm{Cd}^{2+}$ added to Au NP 1 showed that both metal ions activated the system for catalysis, reaching a maximum when a stoichiometry of 1:1 between the TACN head group and the metal ion was obtained $\left([\mathrm{TACN}]=\left[\mathrm{Cu}^{2+}\right.\right.$ or $\left.\mathrm{Cd}^{2+}\right]=20 \mu \mathrm{M}$, Figure $\left.1 \mathrm{~b}\right)$. The sharp transition to the plateau-level at this ratio indicates that metal binding occurs under saturation conditions. Importantly, for a $1: 1$ ratio of $[\mathrm{TACN}]:\left[\mathrm{M}^{2+}\right]$, the rate acceleration was significantly higher for $\mathrm{Au} \mathrm{NP} \mathbf{1} \cdot \mathrm{Cu}^{2+}(9$ times, red squares) than for Au NP 1. $\mathrm{Cd}^{2+}(2.5$ times, green squares) when compared to the background (Figure $1 \mathrm{~b}$, dashed line). It is pointed out that the absolute activities of the $\mathrm{Cu}^{2+}$ and $\mathrm{Cd}^{2+}$ systems are much lower compared to that of the analogous $\mathrm{Zn}^{2+}$ system that we have studied previously. ${ }^{[12,17,18]}$ Yet, the more accessible redox-chemistry of $\mathrm{Cu}$ and $\mathrm{Cd}$ made us focus on these metals, despite the lower catalytic activity. Second, the difference in terms of binding affinity for the TACN group is about six orders of magnitude in favor of $\mathrm{Cu}^{2+}\left(\log K_{\mathrm{TACN} \cdot \mathrm{Cu}^{2+}}=15.4\right.$ and $\log K_{\mathrm{TACN} \cdot \mathrm{Cd}^{2+}}=$ 9.3), ${ }^{[20]}$ resulting in complete displacement of $\mathrm{Cd}^{2+}$ ions from the NP-bound TACN head groups upon the addition of just an equimolar amount of $\mathrm{Cu}^{2+}$ ions. The difference in the activity of the $\mathrm{Cu}^{2+}$ and $\mathrm{Cd}^{2+}$ systems provides a means to upregulate the catalysis by exchanging $\mathrm{Cd}^{2+}$ for $\mathrm{Cu}^{2+} \cdot{ }^{[21]}$ Finally, $\mathrm{Cu}^{2+}$ and $\mathrm{Cd}^{2+}$ metal ions were chosen for their different standard reduction potentials (respectively -0.40 and $+0.34 \mathrm{~V}$ for $\mathrm{Cd}^{2+}$ and $\mathrm{Cu}^{2+}$, relative to the standard hydrogen electrode). ${ }^{[22]}$

We focused our initial investigations on the electrochemical generation of metal ions from a source in order to switch on catalytic activity. To that purpose, we used a carbon chip ${ }^{[23]}$ previously coated with a film of $\mathrm{Cu}^{0}$. The deposition was carried out by dipping the electrode into an aqueous solution of $\mathrm{Cu}\left(\mathrm{NO}_{3}\right)_{2}$ and by applying a fixed reductive potential of
$-1.0 \mathrm{~V}$ vs. $\mathrm{Ag} / \mathrm{AgCl}^{[22]} \mathrm{Cu}^{2+}$ ions were released from the electrode into a buffered solution containing Au NP 1 and HPNPP by applying a potential oxidative ramp from -0.3 to $0.5 \mathrm{~V}$ vs. $\mathrm{Ag} / \mathrm{AgCl}$ for 60 seconds. We employed square wave voltammetry (SWV; Supporting Information, Figure S4), which quantitatively suggested that about $20 \mu \mathrm{M}$ of $\mathrm{Cu}^{2+}$ was electrochemically released from the electrode. ${ }^{[22]}$ The absence of NP precipitation and/or aggregation was proven by a combination of UV/Vis spectroscopy, DLS and TEM analyses, confirming that Au NP $\mathbf{1}$ is stable under the release conditions (Supporting Information, Figures S6-S8). Kinetic measurements (Figure 2) of the initial rate of HPNPP transphosphorylation confirmed that the catalytic system achieved the same activity after the electrochemical release of $\mathrm{Cu}^{2+}$ $\left(v_{\text {init }}=7.4( \pm 1.2) \times 10^{-9} \mathrm{M} \mathrm{s}^{-1}\right)$ as compared to manual addition $\left(v_{\text {init }}=7.7( \pm 1.2) \times 10^{-9} \mathrm{M} \mathrm{s}^{-1}\right)$. Control experiments confirmed that, without application of the potential, the HPNPP transphosphorylation occurred at a low rate, which is comparable to Au NP 1 in the absence of metal ions (Supporting Information, Figure S5). Quantitative ICP-MS analysis confirmed that the concentration of electrochemically released $\mathrm{Cu}^{2+}$ was consistently above the concentration of the NPbound TACN head groups $(20 \mu \mathrm{M}$; Supporting Information, Table S1), confirming the results initially suggested by SWV (Supporting Information, Figure S4). It is noted that an excess of $\mathrm{Cu}^{2+}$, with regards to the concentration of head groups, does not affect the catalytic activity of the system, as the metal

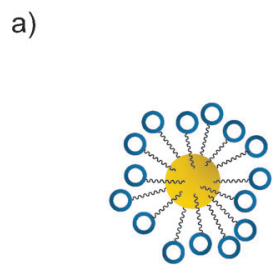

Au NP 1

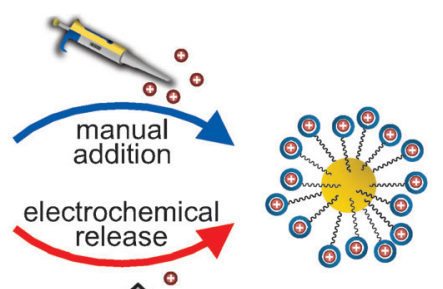

Au NP 1·Cu ${ }^{2+}$

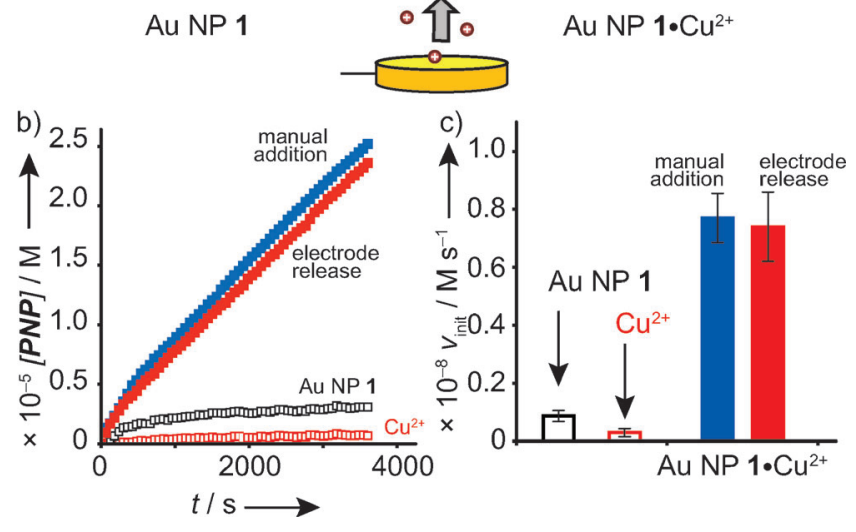

Figure 2. a) Comparison of the efficacy of electrochemical delivery of metal ions as compared to manual addition. b) Example of PNP. formation upon the electrochemical (red) or manual (blue) delivery of $\mathrm{Cu}^{2+}$ metal ions to a solution of Au NP $1([T A C N]=20 \mu \mathrm{M})$ and HPNPP (1 mM). For comparison also the traces for only Au NP 1 and $\mathrm{Cu}^{2+}$ are given. c) Averaged initial rates ( $v_{\text {init }}$, three independent measurements for each trace) for the HPNPP transphosphorylation obtained from the experiments shown in (a). Error bars: \pm 1 s.d.

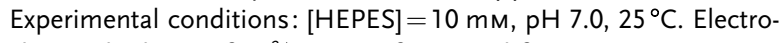
chemical release of $\mathrm{Cu}^{2+}$ : ramp of potential from -0.3 to $0.5 \mathrm{~V} \mathrm{vs}$. $\mathrm{Ag} /$ $\mathrm{AgCl}$ for $60 \mathrm{~s}$. 
ion by itself is not active at these concentrations (see also Figure $1 \mathrm{~b}$ ). The study was then repeated using $\mathrm{Cd}$ instead of $\mathrm{Cu}$. In this case, because of the low oxidation potential of $\mathrm{Cd}^{0}$, controlled release of $\mathrm{Cd}^{2+}$ from the electrode was not possible. ICP-MS (Supporting Information, Table S1) and kinetic experiments confirmed that $\mathrm{Cd}^{2+}$ is spontaneously released from the electrode upon exposure to the solution containing Au NP 1 and HPNPP (Supporting Information, Figure S5). For this reason, the electrode initially covered with $\mathrm{Cd}$ was used as a spatially confined metal source in a displacement experiment (Figure $3 \mathrm{a}$ ). More specifically, a solution containing Au NP $1(20 \mu \mathrm{M})$ and HPNPP (1 mM) was deposited onto the Cd-loaded electrode, which allowed spontaneous $\mathrm{Cd}^{2+}$ release. HPNPP transphosphorylation was then monitored for $30 \mathrm{~min}$ by UV/Vis spectroscopy (Figure $3 \mathrm{~b}$, trace $\mathbf{I}$, green). The efficient delivery of $\mathrm{Cd}^{2+}$ was evidenced by the observed rate $\left(v_{\text {init }}=2.1 \times 10^{-9} \mathrm{M} \mathrm{s}^{-1}\right)$, which a)

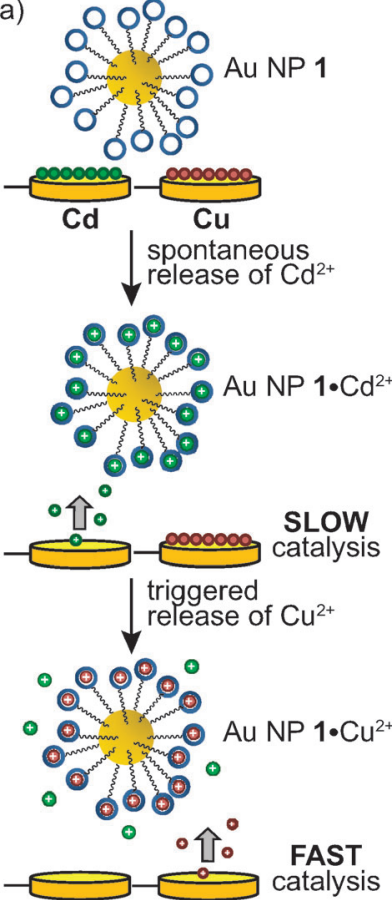

b)

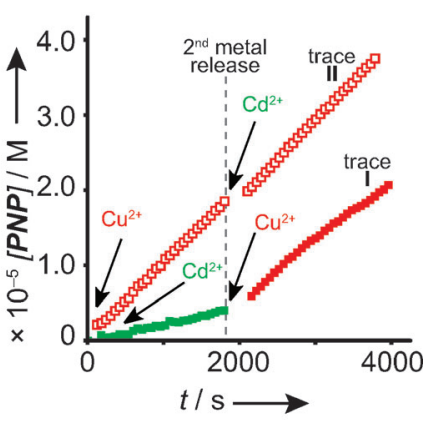

c)

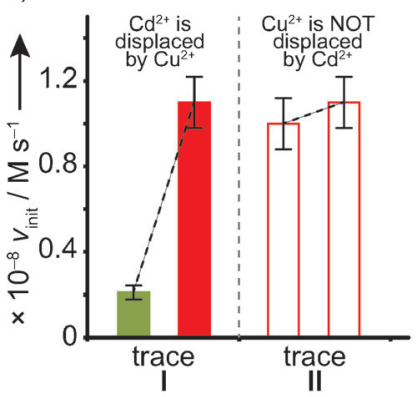

Figure 3. a) Representation of the electrochemical upregulation of catalytic activity. Exposure of Au NP 1 to a $\mathrm{Cd}^{0}$-coated electrode results in a weak increase in catalytic activity. Application of an electrochemical trigger to the same solution with a $\mathrm{Cu}^{0}$-coated electrode causes the release of $\mathrm{Cu}^{2+}$. The released $\mathrm{Cu}^{2+}$ displaces $\mathrm{Cd}^{2+}$ from the TACNhead groups. b) Representative example of a displacement experiment (all experiments were performed in triplicate; see the Supporting Information, Figure S9). Trace I: initial exposure of Au NP 1 to a Cdcoated electrode followed by exposure (after $30 \mathrm{~min}$ ) to a Cu-coated electrode to which an oxidative potential was applied. Trace II: initial exposure of Au NP 1 to a Cu-coated electrode with application of an oxidative potential and subsequent exposure (after $30 \mathrm{~min}$ ) to a $\mathrm{Cd}$ coated carbon chip. PNP-concentration was measured by UV/Vis spectroscopy at $405 \mathrm{~nm}$. Electrochemical release of $\mathrm{Cu}^{2+}$ : ramp of potential from -0.3 to $0.5 \mathrm{~V}$ vs. $\mathrm{Ag} / \mathrm{AgCl}$ for $60 \mathrm{~s}$. c) Averaged rates of HPNPP transphosphorylation after exposure of Au NP 1 to the different carbon electrodes described in (b). Experimental conditions:

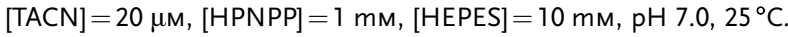
Error bars: \pm 1 s.d. calculated from three independent measurements. corresponded to that of Au NP $\mathbf{1} \cdot \mathrm{Cd}^{2+}\left(v_{\text {init }}=2.0( \pm 0.3) \times\right.$ $10^{-9} \mathrm{M} \mathrm{s}^{-1}$ upon manual addition of $\left.\mathrm{Cd}^{2+}\right)$. Next, the same solution was re-deposited on a $\mathrm{Cu}$-loaded electrode and a potential ramp from -0.3 to $0.5 \mathrm{~V}$ vs. $\mathrm{Ag} / \mathrm{AgCl}$ was applied, after which the kinetic measurements were continued for an additional 30 minutes. A clear increase in the rate of PNPformation was observed ( $v_{\text {init }}$ from $2.1 \times 10^{-9}$ to $1.1 \times 10^{-8} \mathrm{M} \mathrm{s}^{-1}$, Figure $3 \mathrm{~b}$, trace $\mathbf{I}$, red), which is in full agreement with the value obtained when $\mathrm{Cu}^{2+}$ was manually added or electrochemically released in the presence of Au NP $\mathbf{1}$. This demonstrates the effective displacement of $\mathrm{Cd}^{2+}$ by $\mathrm{Cu}^{2+}$ from the monolayer resulting in upregulation of catalytic activity. It was important to observe that the rate of PNPformation did not change at all when $\mathrm{Cd}^{2+}$ was released in a solution containing Au NP 1. $\mathrm{Cu}^{2+}$ and HPNPP, confirming that $\mathrm{Cd}^{2+}$ does not displace $\mathrm{Cu}^{2+}$ from the monolayer (Figure $3 b$, trace II, empty squares).

The described experiments demonstrate that $\mathrm{Cu}^{2+}$ ions can be efficiently delivered through an electrochemical input for the activation of a pre-catalyst. However, full electrochemical control over catalytic activity is achieved only when catalyst activation is a reversible process. ${ }^{[24,25]}$ The reversibility of the electrochemical activation of the system was investigated using $\mathrm{Cu}^{2+}$ (Figure 4a). As before, $\mathrm{Cu}^{2+}$ was released from a prepared electrode into a buffered solution containing Au NP 1 and HPNPP after which the rate of PNP-

a)
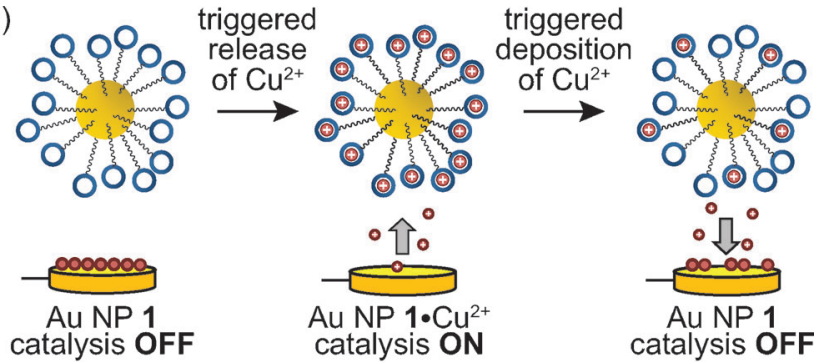

b)

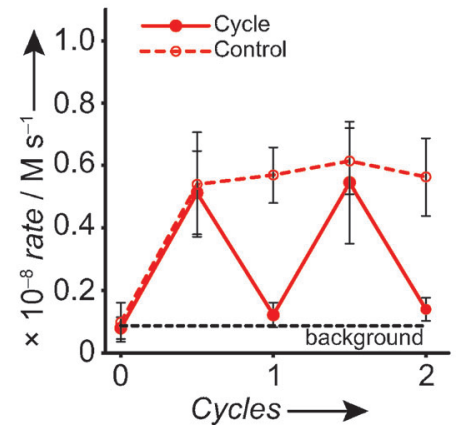

Figure 4. a) Representation of the reversible activation of Au NP 1 driven by the electrochemically controlled release and deposition of $\mathrm{Cu}^{2+}$-ions on the electrode. b) Rate of HPNPP transphosphorylation after two cycles of activation/deactivation of Au NP 1. The control experiment indicates the observed rate when Au NP 1 was just activated once by the electrochemical release of $\mathrm{Cu}^{2+}$ at the start of the experiment. Experimental conditions: $[\mathrm{TACN}]=20 \mu \mathrm{M}$,

$[\mathrm{HPNPP}]=1 \mathrm{~mm},[\mathrm{HEPES}]=10 \mathrm{~mm}, \mathrm{pH} 7.0,25^{\circ} \mathrm{C}$. Error bars: $\pm 1 \mathrm{s.d}$. calculated from three independent measurements. Electrochemical release of $\mathrm{Cu}^{2+}$ : ramp of potential from -0.3 to $0.5 \mathrm{~V} v \mathrm{vs}$. $\mathrm{Ag} / \mathrm{AgCl}$ for $60 \mathrm{~s}$. Electrochemical deposition of $\mathrm{Cu}^{2+}$ : fixed potential of $-1.0 \mathrm{~V}$ vs. $\mathrm{Ag} / \mathrm{AgCl}$ for $10 \mathrm{~min}$. 
formation was measured for 30 minutes. Next, the same solution was deposited on a clean electrode and a fixed reductive potential of $-1.0 \mathrm{~V}$ vs. $\mathrm{Ag} / \mathrm{AgCl}$ was applied for 10 min to re-deposit $\mathrm{Cu}^{2+}$ as $\mathrm{Cu}^{0}$ onto the electrode surface. Control experiments performed by UV/Vis spectroscopy, DLS and TEM analyses confirmed that the monolayerprotected $\mathrm{Au}$ nanoparticles were stable under these conditions (Supporting Information, Figures S10-S12). Furthermore, $\mathrm{UV} / \mathrm{Vis}$ titration experiments of $\mathrm{Cu}^{2+}$ to a solution of Au NP 1 after application of the reducing conditions confirmed no changes in the ability of TACN to complex $\mathrm{Cu}^{2+}$ (Supporting Information, Figure S13). ${ }^{[17]}$ Importantly, continuation of the reaction monitoring by UV/Vis revealed that the rate of PNP-formation $\left(v_{\text {init }}=1.2( \pm 0.4) \times 10^{-9} \mathrm{M} \mathrm{s}^{-1}\right)$ had dropped to the background rate observed for Au NP 1, demonstrating that $\mathrm{Cu}^{2+}$ was sufficiently depleted from the system to inhibit catalytic activity. To fully demonstrate reversibility, a second cycle of activation (using a new electrode with freshly deposited $\mathrm{Cu}$ ) and deactivation was performed with the same solution. Notably, when the system was electrochemically re-activated (from Au NP 1 to Au NP 1. $\mathrm{Cu}^{2+}$ ), the PNP rate of formation was strictly comparable, within experimental error, to that measured for a control experiment monitored for the same length of time where the oxidative potential was applied only at the beginning of the analysis (Figure 4, dashed line).

In conclusion, we have shown the reversible electrochemical regulation of a supramolecular nanocatalyst. Metal ions have been electrochemically released from a pre-coated electrode and complexed by the pre-catalytic system resulting in its activation. This mechanism of catalyst activation permitted the upregulation of catalytic activity through the electrochemical release of $\mathrm{Cu}^{2+}$-metal ions possessing a higher affinity for the macrocyclic ligands compared to $\mathrm{Cd}^{2+}$. Finally, the reversibility of the process was demonstrated by showing that the re-deposition of $\mathrm{Cu}^{2+}$ on the electrode resulted in a loss of catalytic activity. These results show that electrochemistry is a very effective and clean tool for the regulation of the catalytic activity of a supramolecular catalyst. The release of metal ions from a well-defined solid support also opens up the possibility for spatial and temporal control over catalyst activation in systems of higher complexity.

\section{Acknowledgements}

Financial support from the University of Padova (CPDA138148) is acknowledged.
Keywords: gold nanoparticles - nanocatalysis - nanozymes . supramolecular catalysis · supramolecular chemistry

[1] G. M. Whitesides, R. F. Ismagilov, Science 1999, 284, 89-92.

[2] R. F. Ludlow, S. Otto, Chem. Soc. Rev. 2008, 37, 101-108.

[3] S. C. Warren, O. Guney-Altay, B. A. Grzybowski, J. Phys. Chem. Lett. 2012, 3, 2103-2111.

[4] E. Mattia, S. Otto, Nat. Nanotechnol. 2015, 10, 111-119.

[5] M. J. Wiester, P. A. Ulmann, C. A. Mirkin, Angew. Chem. Int. Ed. 2011, 50, 114-137; Angew. Chem. 2011, 123, 118-142.

[6] H. Wei, E. K. Wang, Chem. Soc. Rev. 2013, 42, 6060-6093.

[7] L. Pasquato, P. Pengo, P. Scrimin, J. Mater. Chem. 2004, 14, 3481 3487.

[8] Y. Lin, J. Ren, X. Qu, Acc. Chem. Res. 2014, 47, 1097-1105.

[9] C. Pezzato, S. Maiti, J. L.-Y. Chen, A. Cazzolaro, C. Gobbo, L. J. Prins, Chem. Commun. 2015, 51, $9922-9931$.

[10] Z. Y. Zhou, N. Tian, J. T. Li, I. Broadwell, S. G. Sun, Chem. Soc. Rev. 2011, 40, 4167-4185.

[11] L. J. Prins, Acc. Chem. Res. 2015, 48, 1920-1928.

[12] F. Manea, F. B. Houillon, L. Pasquato, P. Scrimin, Angew. Chem. Int. Ed. 2004, 43, 6165-6169; Angew. Chem. 2004, 116, $6291-$ 6295.

[13] C. G. Vayenas, M. M. Jaksic, S. I. Bebelis, S. G. Neophytides, The electrochemical activation of catalytic reaction in Modern Aspects of Electrochemistry, Springer US, Boston, 1996.

[14] M. W. Kanan, D. G. Nocera, Science 2008, 321, 1072-1075.

[15] A. J. D. Magenau, N. C. Strandwitz, A. Gennaro, K. Matyjaszewski, Science 2011, 332, 81-84.

[16] S. O. Krabbenborg, J. Veerbeek, J. Huskens, Chem. Eur. J. 2015, $21,9638-9644$.

[17] G. Zaupa, C. Mora, R. Bonomi, L. J. Prins, P. Scrimin, Chem. Eur. J. 2011, 17, 4879-4889.

[18] F. Mancin, P. Scrimin, P. Tecilla, Chem. Commun. 2012, 48, 5545 5559.

[19] F. Avenier, J. B. Domingos, L. D. Van Vliet, F. Hollfelder, J. Am. Chem. Soc. 2007, 129, 7611-7619.

[20] R. M. Smith, A. E. Martell, R. J. Motekaitis, NIST Standard Reference Database 46, National Institute of Standards and Technology, Gaithersburg, MD, 2004.

[21] For another example in which metal exchange in a macrocyclic ligand results in upregulation of catalysis, see: Q. Wu, E. V. Anslyn, J. Am. Chem. Soc. 2004, 126, 14682-14683.

[22] S. Ranallo, A. Amodio, A. Idili, A. Porchetta, F. Ricci, Chem. Sci. 2016, 7, 66-71.

[23] F. Ricci, A. Amine, D. Moscone, G. Palleschi, Biosens. Bioelectron. 2007, 22, 854-862.

[24] V. Blanco, D. A. Leigh, V. Marcos, Chem. Soc. Rev. 2015, 44, $5341-5370$.

[25] G. Y. Tonga, Y. Jeong, B. Duncan, T. Mizuhara, R. Mout, R. Das, S. T. Kim, Y.-C. Yeh, B. Yan, S. Hou, V. M. Rotello, Nat. Chem. 2015, 7, 597-603.

Received: May 31, 2016

Published online: 


\section{Communications}

Supramolecular Catalysis

F. della Sala, J. L.-Y. Chen, S. Ranallo,

D. Badocco, P. Pastore, F. Ricci,*

L. J. Prins*

\section{IIII-IIII}

Reversible Electrochemical Modulation of a Catalytic Nanosystem

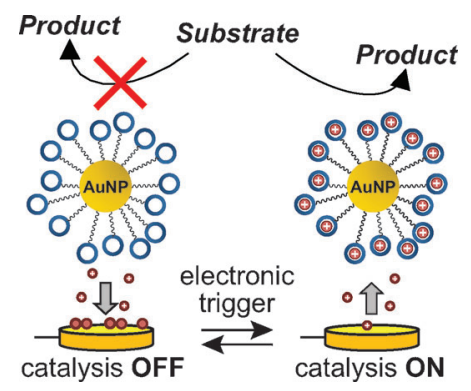

Hop on, hop off: Metal ions are reversibly released from an electrode to regulate the activity of a gold nanoparticle catalyst (see picture). The system catalyzes the cleavage of 2-hydroxypropyl-p-nitrophenyl phosphate and the formation of $p$-nitrophenolate can be monitored by UV/Vis spectroscopy. 